\title{
Participation of Parents in School Governance: A Case Study of Two Eastern Cape Schools: A View from Below
}

\author{
M. P. Mavuso \\ University of Fort Hare, School of further Education and Continuing Studies \\ Alice, 5600, South Africa. pmavuso@ufh.ac.za \\ Dr. N. Duku \\ University of Fort Hare, School of General and Continuing Studies, \\ East London, 5200, South Africa. nduku@ufh.ac.za
}

Doi:10.5901/mjss.2014.v5n3p454

\begin{abstract}
This study investigated the participation of parent SGB members in school governance. It also explored how parent School Governing Body (SGB) members participate in school governance in executing the roles of the SGBs. South African Schools Act 84 of 1996 stipulates that SGBs be constituted of parents who are in majority, teachers, non teaching staff and learners in the case of secondary schools. This study therefore used the qualitative research approach through structured and semi structured interviews and documentary analysis to investigate how parent SGB members participate in school governance. From the findings it emerged that parent SGB members regarded their roles as that of calling meetings, chairing meetings, formulating school policies, ensuring culture of teaching and learning and managing school finances. It also emerged that parent SGB members do not differentiate between their role and that of the SMT. Most SGB subcommittees seem to be dysfunctional and it emerged from the data that parent SGB members regarded educators as persons who should deal with school finances and matters of procurement. The majority of parent SGB members did not know what policies the school must adopt they regarded this as something that is better known by the educators. Hence, parent SGB members understood school governance to be better understood by educators and their role to be more operational than strategic.
\end{abstract}

Keywords: Participation, School governance, School Governing Body

\section{Introduction}

School governance is the involvement of the relevant stake holders such as parents, educators, learners and nonteaching staff in making decisions about how the school should be governed according the provisions of SASA (Duku, 2006). School governance in pre-1994 used to be characterized by authoritarian and exclusive practices (Ibid, 2006). Schools were governed by the school boards or school committees which were not democratically elected (Mbantsane, 2006), and these committees were expected to serve the interests of the Apartheid government. This means that committees did not serve the interests of the communities they represented. They were just agencies of the state carrying out the will of the legislative assembly (Ibid). This landscape was changed after the promulgation of South African Schools Act no 84 of 1996 (SASA). Through this legislation it was anticipated that there would be broad democratic participation of the communities that include parents, teachers and learners in the case of secondary schools. This legislation therefore amongst others envisaged the central role to be played by parents in the education of their children. It was anticipated that SASA legislation would contribute to greater equity, efficiency and improved parental participation that would in turn lead to an enhanced culture of teaching and learning (Bush \& Heystek 2003, van Wyk, 2004 and Duku, 2006). This means that through SASA, democratically elected School Governing Bodies (SGBs) were legislated, through which

The legislation of SASA had its aim to bring about the democratic transformation of society (Adams \& Waghid, 2005). Furthermore, through SASA the government also hoped to redistribute power from central authorities to local authorities such as schools. This, as it was anticipated, would lead to a system that would be sensitive to local dynamics (Weiler, 1990 in Chikoko, 2007). However, some writers such as Soudien (2003) and Duku (2006), criticize SASA for being too much aligned to middle class in quality, and for crafting parental participation in middle class terms, without much regard for the underprivileged societies. "SASA, for instance, makes implicit assumptions about parents; for 
example: that they can all afford personal time to spend on school activities which are not related to any form of remuneration, and that they have the resources to make choices about their children education" (Soudien, 2003; Sayed \& Soudien, 2005 in Duku, 2006: 140). As a result in some communities particularly in rural schools parents seem to rely more on educators on matters of school governance (Duku, 2006; Mncube, 2009). Consequently this leads to school governance not following the direction anticipated in SASA, more especially in rural areas.

Amongst the reasons for SASA not to yield the anticipated goals, particularly on parental participation are the power dynamics experienced between the different sectors of the communities, and the power dynamics between the parents and the educators (Brown and Duku, 2007; Brown \& Duku, 2008, Duku, 2006; Heystek, 2004). On the power dynamics between the different community stakeholders Brown \& Duku (2007) highlight issues of social identities such as gender, tradition and micropolitics within the school communities as privileging the historically privileged groups in school participation. They note that, as historically biased by the tradition, leadership roles in school governance are assigned to elderly particularly males, and elderly married women (Duku, 2006). Besides the community social dynamics that seem to be blocking the promotion of the SASA ideals, teacher-parent dynamics are also alleged to also play a role.

Duku (2006), for instance notes that parents consider school governance to be better understood by teachers, and therefore more qualified to carry out these duties. This amongst others is due to literacy levels of the parents which sometimes results to the lack of commitment (Mbasa \& Themane, 2002). Parents tend to be unfamiliar with school meeting procedures and in most cases experience a problem that is used in the documents in these meetings. This leads to principal dominate the parents in school governance (Ibid, 2002).

In spite of the criticism raised above here, there seem to be an overwhelming agreeing on the importance of parental participation in school governance (see Sayed, 2002; Suzuki, 2002; Duku, 2006; Mbantsane,2006; Lusaseni,1998; Maclure,1994; Mathonsi, 2000; Heystek,2004; Lewis \& Naidoo,2005 and Mncube, 2009). As other social dynamics seem to frustrate the achievement of SASA philosophy, the concern is what type of partnership is there between the teachers and the parents. Hence this paper aims to unpack the kind of participation by parent SGB members in school governance.

The research question this paper aims to address is:

How do parent SGB members participate in School Governance?

\section{Theoretical Framework}

The study was informed by Arnstein's (1967) model on Ladder of participation 'ladder of participation' framework as developed by Arnstein (1967) is one aspect of the theory of participation and the aspect used in this research. The ladder of participation consists of eight rungs with the lowest rung depicting the lowest of non - participation level. As the ladder goes up the level of participation improves with rungs 7 and 8 referred to as delegated power and citizen control respectively. (Ibid, 1967). This framework is used to classify different ways of participation. Arnstein (1967) found that most techniques of public participation can be used in ways that do not authentically engage the citizenry. Her Ladder of Participation depicts citizen participation in community planning and decision making activities, which she characterizes as Nonparticipation, Tokenism; and Citizen Power or genuine participation. This ladder shows a distinction between different characteristics and levels of participation made by low intensity of participation at the bottom, and higher intensities of participation end up higher the ladder. For this research all the characteristics are relevant as lenses for analyzing parent participation in school governance of the selected Eastern Cape communities.

Participation is described by many writers as a process of empowerment of marginalised people; people's involvement in decision-making processes; and, a process through which stakeholders influence control of development initiatives, decisions and resources (Buhler, 2001 and Sidorenko, 2006). Participatory approaches to 'communitybuilding', policy-making, and development are becoming increasingly popular although they are questioned and challenged in other corners of the world (Buhler,2001). However, some writers suggest that it is more useful to see participation in terms of a continuum on which participation moves from being merely nominal and representing little meaningful or direct involvement to a transformative participation, which results in people's empowerment and in direct and effective participation. In general, the participatory approach is justified in terms of sustainability, relevance and empowerment (Arstein, 1967).

The idea of participation as noted by Arnstein (1967) is like eating spinach, no one is against it in principle because it is good for you. This act of faith is based on three main views: that participation is intrinsically a good thing especially for the participants, that a focus on getting the techniques right is the principal way of ensuring the success of such approaches and that considerations of power and politics on the whole should be avoided as divisive and 
obstructive. Furthermore, literature on participation is often rather vague on the incentives which will persuade people to participate (Ibid). Participation is supposed to depend on a mobilisation process, upon the realization amongst participants that high levels of involvement are for their own good. Many policy approaches link participation to social responsibility, to characterise non-participation as irresponsibility, and at the same time to define benefits, which may in fact be long term, cumulative and community wide, as of immediate productive advantage to the individual.

\section{Research Methodology}

This study adopted qualitative research methodology within the parameters of the interpretive paradigm. Qualitative research is an approach in which researchers are concerned with understanding the meaning which people attach to their experiences or phenomenon within their society (Ritchie \& Lewis, 2003). The researcher used the qualitative research because this study was about investigating parental participation in school governance and the meaning the parents attach to their participation in school governance. The qualitative approach puts emphasis on the knowledge and practice that are studied at the local level (Flick, 2006). Interpretive paradigm is about understanding the everyday experiences of people in a specific area or historic setting. (de Vos, 2002). It is about epistemology that advocates that it is necessary for the researcher to understand human's roles as social actors and the meaning the humans give these roles (Ibid, 2006). This research falls within this paradigm in that it investigates how parents participate in school governance.

Two rural primary schools were selected in this study. These schools were sampled because they were both primary schools in black, rural areas. The sample comprised of 36 respondents. Of the 36 respondents 2 were school principals 4 SGB educators, 2 SGB chairperson, 2 SGB secretaries and 2 SGB treasurers. There were 2 SGB nonteaching staff members and the rest were non SGB parents.

The researcher used multiple data collection methods namely: structured interviews, semi- structured interviews, document analysis and non-participatory observations. The interview is any formal person - to - person interaction between two or more people with a specific purpose or objective in mind on a specified date and time (Kumar, 2005). In using the structured interviews the researcher probed the respondents reasoning because he wanted them to respond to a standard set of questions. A structured interview is a technique that is easy to administer because it permits the researcher to have a well defined role of sitting with questionnaire in his/her lap (Plummer, 2001). In this type of research method, a researcher gained the relative security of knowing both what to ask and what was likely to be heard in reply (Plummer, 2001). This means therefore that structured interviews used pre-established questions that are asked in a predetermined order (O'Leary, 2004). Semi-structured interviews are neither fixed nor fully free and yet they are a flexible research technique or method (O'Leary, 2004). This means that the order of the questions as advised by (Robison, 2002) was changed depending on the situation the researcher encountered. With the use of semi-structured interviews the researcher wanted the respondents to expatiate as much as they could on certain points. This also helped the researcher to probe respondent's reasoning and to ask clarity seeking questions. The interviews were conducted in the respondents' home and they were tape recorded verbatim. The documentary analysis was done with the aim of understanding the participants actions and meaning they attach to their actions. SGB minute books and parent meeting minute books were analysed. Document analysis is the situation in which the reader reads and analyses important documents such as minutes of the meetings, newspaper articles and historical archives and previously gathered census data. It is the process of which is done with the aim of understanding the participants' actions and the meaning they attach to their actions or events (O'Leary, 2004, Mouton, 2005; Plummer, 2001, O'Leary, 2004).

\section{Presentation and Discussion of Findings}

\subsection{Politics of participation in the SGB}

This section discusses the findings that emerged from the data and relates them to the literature that has been reviewed above. The concepts that were discussed earlier on serve as lenses by which the parental participation in SGBs is viewed. In this section the researcher discussed the findings from both schools.

Regarding the calling of the meetings it emerged from the data that the principal is the person who calls school meetings. One participant noted that, "The principal is the head of the school therefore it is his role to call the SGB meetings". This may be an indication that the principal is the person who is knowledgeable in matters of school governance as he represents the DoE. Even some respondents referred to him as the Chief Executive Officer (CEO) of 
the school which means he is superior person in matters of school governance. This is practice is according to Arnstein's Ladder of participation Theory which refers to 'tokenism' as one level in the ladder of participation. In this level Arnstein noted that have -nots are allowed to hear and have a voice through informing and consultation (Arnstein, 1967). In most cases it was expected that the principal informs the parents of the developments in the DoE. Some writers like Farrel (2001) view the partnership between the principal and the SGB chairperson as vital in school governance. The principal represent the DoE while the SGB chairperson represents the interest of the community (Ibid, 2001). However, the partnership seemed to be unequal as it was the principal in most cases who initiated meetings with the SGB chairperson.

The issue of collaboration as raised by Heystek (2004) seemed to prevail between the SGB chairperson and the principal in that the principal seemed to have sessions with the SGB chairperson. One SGB chairperson commented that,

Besides chairing the SGB and parents meetings, I monitor the activities of the SGB and I am the first person to be informed by the principal of any development in the school. Together with the principal we decide on the date that we should call SGB meeting.

After the session between the principal and the SGB chairperson, an SGB meeting would be called and it was reported to be the role of the principal to call these meetings which was indication that parent SGB members' participation in school governance was limited as they regarded calling SGB meeting as the role of the principal.

One school principal further commented that:

He is the person who assists with the school governance, who comes to school regularly. He only assists in matters of school governance not in matters of school management. He assists the principal in seeing to it that the school runs effectively and efficiently.

The majority of the respondents, as indicated above, noted that it is the role of the chairperson to chair SGB and parent meetings. However, there were a few respondents who indicated that the chairing of the school meetings is done by the principal and the SGB chairperson. The fact that it was reported that principals sometimes chair the SGB meetings may be an indication that they overstep the role of the SGB chairperson in school governance. The overstepping of the SGB chairperson's roles by the principal is what Heystek (2004) refers to as 'power plays' which may be conscious or unconscious. The power plays happen when the principal dominates the rest of the SGB or the SGB chairperson dominates the principal (Ibid, 2004). This may also be an indication that parent SGB members are unsure of their participation in school governance.

Regarding parent SGB members' participation in the formulation of policies and their implementation, the majority $(80 \%)$ of respondents reported that it was the role of the SGB to formulate and ensure the implementation of school policies. Another $80 \%$ reported that parents formulate school policies in their general meetings. This was an indication that parent SGB members were not sure at which level of school governance was their participation in matters of policy formulation required. However, this was an indication that parental participation was enhanced since parents were reported to make decisions on school policy formulation, and perhaps in principle they knew that they are expected to participate in policy formulating business. This was therefore consistent with what Lewis \& Naidoo (2005) refer to as involving stakeholders in making decisions by consensus. However, the SGB has the power to formulate policies within the prescribed parameters of the DoE. This means that the SGB cannot formulate a policy that is contrary to the broader policy of the DoE. For instance, the SGB is required to have policy on admissions and yet the DoE has a policy on admissions on matters pertaining to age requirements and timeframes for admissions.

When asked about his role, one SGB chairperson replied:

"I ensure that rules and policies of the school are implemented. For example when a learner misbehaves I see to it that proper disciplinary measures are followed".

One school principal reported that:

Educators sit in a meeting and come up with proposals on certain issues. These proposals are taken to the SGB by those educators who are in SGB. The SGB discusses and draft a policy to be presented to the parents meeting. The parents are the last persons to have a say and it is endorsed as a policy of the school by the parents.

The fact that the SGBs reported regularly to parents on school progress and require parents to have a say and to 
make some decisions on the education of their learners was a reflection of what Maclure (1994) calls decentralisation of education. The majority of respondents view the role of SGB as that of formulating school policies and this is consistent with what Mathonsi (2006) view as delegation of powers to the local people. However, their participation and decision making is limited in that they operate under the readymade policies of the DoE. This is what Arnstein (1967) refers to as 'placation'. Placation is just a higher or advanced level tokenism because the ground rules allow have-nots to advise, but retain for the power holders the continued right to decide. It allows citizens to advise or plan ad infinitum but retains for power holders the right to judge the legitimacy or feasibility of the advice (Ibid,1967).

SASA requires that the SGBs establish SGB committees which their majority membership is parents. The aim of establishing these SGB sub committees is to enable the SGB to execute its roles effectively. This means that, according to Arnstein (1967) the system of school governance allows for 'citizen control' where parents are expected to be in majority in SGBs and their sub committees. Lenin (2009) further noted that a situation where partners are actively involved in a business or business relationship as active partnership. However most of the SGB sub committees were reported to be dysfunctional and their tasks were performed by the SGBs in which the educators play a dominant role. This means therefore that though the involvement of parents in decision making was an indication of democratization of school governance, what Mathonsi (2001) referred to as 'delegation of powers' within the SGB was not prevalent. That most of the SGB subcommittees were dysfunctional makes the SGBs look like a nerve centre that does not have enough branches to support it in executing its duties. No other persons were reported as serving in the SGB subcommittees. This was an indication that community involvement was limited to making decision at the level of parent meetings. On certain school governance matters that required some expertise, the community was not involved. This was despite the SASA (1996) prescription that the SGB should appoint on the basis of expertise other persons who are not members of the SGB to serve in these committees.

Regarding the management of school finances it emerged that this is largely dependent on the educators. In this regard the issue of mentoring as argued by Crawford \& Earley (2004) and Mathonsi (2001) emerged as it seemed educators and the principal assisted the parent SGB members in financial management. It was reported that the principal gives direction on many occasions on matters of school finance. This may indicate the fact that parent SGB members needed a person with expertise to guide them on SGB financial matters.

There were no sessions that were reported that dealt with the book keeping school finances by the finance committee. The processes of budgeting were apparently not done by the SGB finance subcommittee. It also emerged from the report that the finance committee meetings are not held regularly, that is, there was no schedule of meetings by finance committee. There were no reports on the procedure followed when the school purchases goods except for educators having to secure quotations from different shops. The processes that are followed during cheque requisition were also not reported. This means, therefore, that parent SGB members need support for them to be able to perform their roles effectively.

It also emerged from the data that SGB chairperson and other SGB members sometimes visit school to check that teaching is taking place. This may be an indication that the parent SGB members do not understand their roles regarding ensuring culture of teaching and learning. SASA (1996) prescribes that the principal of a school see to that all the education programmes and curriculum activities are implemented and that there is academic improvement in a school. This therefore means that some parent SGB members do not differentiate between the roles of the SGB and those of the SMT.

It emerged from the data that the SGB and non SGB members seem to have similar conceptions of the factors that affect school governance. These included commitment, punctuality, dedication, trust and respect. Amongst other factors that the respondents reported was the lack of support from the Department of Education. Crawford \& Earley (2004) indicated that the lack of mentoring given to SGBs in executing their roles brings about factors that are detrimental to the school governance.

\section{Conclusion}

From the above presentation one could deduce the fact that parents, educators and principals have different conceptions and assumptions about the roles of parents in school governance. It emerged from the data that parents are involved in decision making as both SGB members and as parents. However educators seem to be playing a leading role in matters pertaining school finances, formulation of policies and ensuring the culture of teaching and learning. Parents are regarded as a crucial stakeholder in their children's education. However, they seem to be unable to distinguish between the roles of the SMT and those of the SGB concerning the ensuring culture of teaching and learning. Females are in the 
majority in the SGBs although they were reluctant to assume the leadership positions as they see it as something meant for males. It also became clear that SGB subcommittees which parents are members of do not support the SGB. Furthermore, the majority of parents regard school governance as something better understood by the educators.

\section{References}

Adams, F. \& Waghid, Y. (2005). In defence of deliberative democracy: challenging less democratic school governing body practices, South African Journal of Education, 25(1): 25-33.

Arnstein, S.R.(1967). A ladder of citizen participation, JAIP, pp. 216-224.

Brown, B. \& Duku, N. (2007). Parents' participation in school governance in South Africa: social identies and policy implications, Journal of Educational Studies, 6 (2), pp. 139-178.

Brown, B. \& Duku, N. (2008). Negotiated Idendities: Dynamicis in parent participation in school governance in rural Eastern Cape schools and Implication for school leadership, South African Journal of Education, 28(3),pp431-450.

Bühler, U. (2001). Participation 'with Justice and Dignity': Beyond 'the New Tyranny'. United Kingdom, University of Bradford.

Burde, D. (2004). Weak State, Strong Community? Promoting Community Participation in Post-Conflict Countries, Current Issues in Comparative Education, 6(2). pp.73-87, Teacher college, Columbia University.

Bush, T \& Hestek, J.(2003). School Governance in the New South Africa, Compare, 7.

Carnaby, P. (2009). National libraries in the digital age, leadership and Collaboration, Wellington: IFLA.

Chikoko, V. (2007). Negotiating roles and responsibilities in the context of decentralized school governance:A case study of one cluster of schools in Zimbabwe. International Studies in Educational Administration, 35(1), 22 - 40.

Cleaver, F. (1999). 'Paradoxes of Participation: Questioning Participatory Approaches to Development', Journal of International Development, Vol.11, pp. 597-612.

Cleaver, F. 2001, 'Institutions, Agency and The Limitations of Participatory Approaches to Development', in B. Cooke and U. Kothari, eds., Participation: The New Tyranny?, London: Zed Books.

De Vos, A., Srydom, H., Fouche, C.B. \& Delport, C.S.L. (2002). Research at Grass Roots, Pretoria: Van Schailk Publishers.

Duku, N. (2006). The exploration of parents' negotiations of their identities in school governance participation in six selected villages, unpublished $\mathrm{PhD}$ thesis, University of Cape Town.

Dunne, M. Akyeampong, K., \& Humphreys, S. (2007). School Processes, Local Governance and Community Participation: Understanding Access, Create, Consortium for research on Transitions and equity, 6, 1-90.

Farrel, M. (2001). Key issues for secondary schools, London, Routledge Falmer.

Flick, U. (2006). An Introduction to Qualitative Research, London, SAGE Publishers.

Heystek, J. (2004). School Governing Bodies- the principal's burden or light of his/her Life, South African Journal of Education, 24(4), 308-312.

Kabacoff, R.I. \& Stoffy, R.W. (2001). Age Difference in Organizational Leadership, A paper presented at the $16^{\text {th }}$ Annual Conference of the Society For industrial and Organizational Psychology, San Diego: California.

Karlson, J. (2002). The Role of Democratic Governing Bodies in South African Schools, Comparative Education, 38(3) 327-336.

Kumar, R. (2005). Research Methodology. London: SAGE Publishers.

Kelly, M.J.M. (1997). Gender Differences and Leadership, A research report submitted in partial fulfillment of the curriculum requirement, Air Force College: Air University.

Kezembe, M.B. (2005). Retracing Footsteps of the Literati: towards an understanding Of literacy development through stories of Malawian Teacher Educator, Dissertation submitted for the partial fulfillment of the requirements for the degree of Doctor of Philosophy in Virginia polytechnic institute and State Unoversity.

Lenin (2009). Partnership and types of partnership, Indiastudychannel.com.

Lewis, S.G. \& Naidoo, J. (2005). School Governance and the Pursuit of Democratic Participation, International Journal of educational Development, 26(4), 415-427.

Ludovina, F. (2002). Fostering Home- School Partnership, Preschool Coordination Project, San Diego.

Lusaseni, P.H. (1998). An investigation of how members of a school governing body perceive and experience their roles, A case study, Rhodes University.

Maclure, R. (1994). Misplaced assumptions of decentralization and participation in rural communities: primary school reform in Burkina Faso, Comparative Education, 30(3), 239-254.

Mathonsi, V. (2000). Transforming governance and management of education-The case for South Africa, Gallagher Estate.

Mbantsane, P.N. (2006). The Financial accountability of School Governing Bodies: unpublished Masters' Degree Thesis, University of Pretoria, Gauteng, South Africa.

Mbasa,T. \& Themane, J. (2002). Stakeholder Participation in School Governance in South Africa, Perspectives in Education, Vol 20(3) $111-116$.

Mncube, V. (2009). Perceptions of the principal's role in the democratic governance in in South Africa, Journal of Educational Administration and History, 41(1) 29-43.

Mestry, R \& Grobler, B. (2007). Collaboration and communication as effective strategies for parental involvement in public schools, Educational Research and Review, 2(7), 176-185. 
Motimele, M. (2005). School Governing Bodies, Education Rights Projects, Wits, Johannesburg.

Mouton, J. (2005). The Practice of Social Research. South Africa: Oxford.

O'Leary, Z. (2004). The Essential Guide to Doing Research. London: SAGE.

Plummer, K. (2001). Documents of life. New Dehli: SAGE.

Ritchie, J. \& Lewis J. (2003). Qualitative Research Practice. London: SAGE.

Robson, C. (2002). Real World Research. UK: Blackwell Publishers.

Sayed, Y. (20020 Democratising Education in a Decentralized System: South Africa policy and practice, Compare, 32(1) 35-46.

Sidorenko, A. (2006). Empowerment \& Participation in Policy Action on Ageing, International Design for All Conference, Rovaniemi, Finland - Full papers Keynotes

Soudien, C. (2003). Constiting and a class' :An analysis of the process of 'integration' in South African Schools, Changing Class.

Suzuki, I. (2002). Parental participation and accountability in Primary schools In Uganda, Compare, 32(2) 243-259.

USAID, (2005). Educational Quality in Developing World, EQ Review, 3 (4), 1-4.

USAID, (2006). Peaks Regional Conference on School Governance in Central Asia, Academy of Educational development, p.1.

Van Wyk, W. (2004). School Governing Bodies: the experiences of South African Educators, South African Journal of Education, 24(1) 49-54.

Xaba, M.I. (2004). Governors or watchdogs? The role of educators in the schooling bodies, South African Journal of Educ 